\title{
Decreased myometrial p160 ROCK-1 expression in obese women at term pregnancy
}

\author{
Margaret O'Brien ${ }^{1 *}$, Shawna Carbin², John J Morrison ${ }^{1}$ and Terry J Smith ${ }^{2}$
}

\begin{abstract}
Background: Obesity is becoming an increasing problem in obstetric practice; it has led to an increase in the risk of caesarean delivery, prolonged pregnancy and dysfunctional labour. It has been postulated that many of these problems are as a result of abnormal myometrial contractility. The RhoA/Rho kinase pathway is involved in calcium sensitisation in the myometrium during labour and contributes to the phosphorylation of myosin phosphatase and thus continued myosin light chain activity, during uterine contractility. The aim of this study therefore, was to investigate the effect of obesity on the expression of various components of the RhoA/ROCK pathway in human myometrium at term pregnancy.

Methods: Protein was isolated from myometrial biopsies obtained at elective caesarean section, at term pregnancy from obese women and from those with a normal body mass index. Western blotting was performed using specific primary antibodies to RhoA/ Rho kinase associated proteins.

Results: The protein expression of p160 ROCK-1 was significantly decreased $(P<0.001)$ in the myometrium from women in the obese cohort $(n=22)$ at term pregnancy, compared to women of those of normal body mass index $(n=15)$. No alteration in expression of the other proteins investigated was noted.

Conclusions: The significant decrease in p160 ROCK-1 protein expression observed in the myometrium of obese women at late gestation may contribute to an inhibitory effect on contractility at labour, due to its contribution to calcium sensitisation and possibly other signalling pathways. These findings are relevant to the concept of compromised myometrial function in obese parturients.
\end{abstract}

Keywords: p160 ROCK 1 protein, Myometrium, Obesity, Term pregnancy

\section{Background}

Obesity is a big health problem in society, and is an increasing one in obstetric practice [1]. A wide variety of perinatal complications are associated with maternal obesity including prolonged pregnancy, less likelihood of spontaneous onset of labour at term, slower cervical dilation, longer duration of labour and an increased risk of intrapartum caesarean delivery $[2,3]$. Increased maternal body mass index (BMI) has also been significantly associated with ineffective uterine contractility [4], and the reasons for this are complex, and have been linked to elevated cholesterol levels (6) and a reduction in intracellular free calcium $\left[\mathrm{Ca}^{(2+)}\right]$ flux in previous reports [5]. These findings suggest a possible dysregulation in myometrial contractility pathways occurs in association with maternal

\footnotetext{
* Correspondence: magsobrien99@hotmail.com

${ }^{1}$ Department of Obstetrics and Gynaecology, Clinical Sciences Institute,

University College Hospital Galway, Galway, Ireland

Full list of author information is available at the end of the article
}

obesity, but there are minimal data to clearly support this hypothesis or explain the potential mechanisms. Adipocytokines have been postulated as having a metabolic role which exerts an inhibitory effect on myometrium in obese parturients. Our group has highlighted that leptin along with other adipocytokines, apelin and ghrelin inhibit uterine contractility in vitro [1,6-8]. However the potential signalling pathways that are involved are unknown.

Uterine smooth muscle contraction is primarily regulated by an increase in intracellular free calcium $\left(\left[\mathrm{Ca}^{2+}\right]_{\mathrm{i}}\right)$, which leads to the activation of calmodulin-dependent myosin light chain kinase (MYLK). MYLK phosphorylates the regulatory myosin light chain (MLC), enhancing actin-myosin ATPase activity to cause contraction [9]. Dephosphorylation of the phosphorylated MLC by myosin phosphatase (MYPT) results in relaxation [10]. Meanwhile, MYPT is inhibited by phosphorylation by the protein kinase, Rho (Ras homolog gene family, member) -associated, coiled-coil

\section{Biomed Central}

(c) 2013 O'Brien et al.; licensee BioMed Central Ltd. This is an Open Access article distributed under the terms of the Creative Commons Attribution License (http://creativecommons.org/licenses/by/2.0), which permits unrestricted use, distribution, and reproduction in any medium, provided the original work is properly cited. 
containing protein kinase 1 (ROCK-1) at positions Thr696 or Thr853, either simultaneously or independently $[11,12]$. MYLK is activated by $\mathrm{Ca}^{2+}$-calmodulin whereas MYPT is inhibited by phosphorylation by $\mathrm{Ca}^{2+}$-independent mechanisms, leading to generation of increased MLC phosphorylation and force for a given intracellular $\mathrm{Ca}^{2+}$ concentration, a phenomenon known as 'calcium-sensitisation' [13]. Human pregnant myometrium expresses Rho regulatory proteins [14], including ROCK-1 and 2 $[15,16]$. There seems to be no significant change in the expression of ROCK-1 or 2 with pregnancy or labour [15-17]. However, in leptin-receptor deficient mice there is an altered contribution of RhoA/ROCK-1 signalling in the contractile activity of myometrium, suggesting leptin suppression of myometrial ROCK-1 and -2 expression and function, resulting in an inability to generate tonic contractions needed for delivery [18]. We therefore hypothesised that the RhoA/ROCK pathway may be linked to abnormal myometrial contractility in obese pregnant women. The aim of this study was to determine the effect of obesity in pregnancy on the expression of Rho and ROCK associated proteins in myometrium at term gestation in obese pregnant women, and in a control group of women with normal BMI.

\section{Methods}

\section{Tissue samples}

Biopsies were obtained at elective caesarean section in the third trimester of pregnancy in the Department of Obstetrics and Gynaecology, University College Hospital, Galway, Ireland. Ethical committee approval for tissue collection was obtained from the Research Ethics Committee at University College Hospital Galway and recruitment of patients was by informed written consent. The BMI calculation for women recruited was based upon weight and height measurements obtained at the first antenatal visit. Normal BMI was classified as 18.5 to $24.9 \mathrm{~kg} / \mathrm{m}^{2}$ and the obese category BMI was classified as $30 \mathrm{~kg} / \mathrm{m}^{2}$ or greater. The biopsy specimens were excised from the upper portion of the lower segment of the uterus. Myometrial samples were carefully dissected to minimise decidual inclusion. Immediately upon collection, the tissue was snap-frozen in liquid nitrogen in the operating theatre and stored at $-80^{\circ} \mathrm{C}$.

\section{Study patients}

Biopsies were obtained at elective caesarean section $(n=37)$. The reasons for elective caesarean section in the normal BMI cohort $(n=15)$ included as follows: 1 previous caesarean section $(n=4), 2$ previous caesarean sections $(n=5)$, breech presentation $(n=3)$, Intrauterine growth restriction (IUGR) $(n=1)$, polyhydraminos $(n=1)$ and previous endometrial ablation $(n=1)$. The reasons for elective caesarean section in the obese category $(n=22)$ were as follows: 1 previous caesarean section $(n=8), 2$ previous caesarean sections $(n=3), 3$ previous caesarean sections $(n=1)$, breech presentation $(n=5)$, previous vaginal surgery $(n=1)$, congenital hearing impairment $(n=1)$, foetal macrosomia $(n=1)$, previous myomectomy $(n=1)$ and previous third degree perineal tear $(n=1)$ The patient demographic data for both sets of samples is presented in Tables 1 and 2 .

\section{Protein isolation}

Human myometrial tissue was disrupted in liquid nitrogen using a pestle and mortar prior to homogenisation in ice cold lysis buffer [19] containing $10 \mathrm{mM}$ HEPES pH 7.5, 10 $\mathrm{mM} \mathrm{MgCl2,} 5 \mathrm{mM}$ KCL, 0.1\% Triton X-100, $0.1 \mathrm{mM}$ EDTA pH 8 (Sigma Aldrich, Dublin, Ireland) and a complete mini-protease inhibitor tablet (Hoffmann-La Roche Ltd., Basel, Switzerland) [20]. Cellular debris was removed by centrifugation at 5,000 $\times \mathrm{RPM}$, at $4^{\circ} \mathrm{C}$ for 10 minutes. 5 X Laemmli buffer containing $50 \mathrm{mM}$ DTT was added to the supernatant, samples were used or stored at $-80^{\circ} \mathrm{C}$.

\section{Protein gel electrophoresis}

The protein preparation was resolved by electrophoresis on Mini-PROTEAN TGX precast $10 \%$ or $12 \%$ (Biorad, Hercules, CA, USA) SDS (w/v) polyacrylamide gel electrophoresis (SDS-PAGE) gels at 30-50 Volts (V) at room temperature for 1-2 hours (BioRad, USA) in a buffer containing $25 \mathrm{~mol} \mathrm{l}^{-3}$ Tris base, $\mathrm{pH} 8.3,19.2 \mathrm{~mol} \mathrm{l}^{-2}$ glycine, and $0.1 \%(\mathrm{w} / \mathrm{v})$ SDS. The separated proteins were transferred to Immobilon-P transfer membranes (Millipore, Billerica, MA, USA) at a constant voltage of $25 \mathrm{~V}$ at $4^{\circ} \mathrm{C}$ overnight in transfer buffer containing $25 \mathrm{~mol} \mathrm{l}^{-3}$ Tris base, $192 \mathrm{~mol} \mathrm{l}^{-3}$ glycine, and 20\% methanol (v/v), highperformance liquid chromatography (HPLC) grade (SigmaAldrich, Dublin, Ireland). To ensure transfer and equal loading of proteins, blots were stained with Ponceau S solution (Sigma-Aldrich, Ireland) for 5 minutes, followed by washing with de-ionised water. Membranes were blocked upon incubation for 1 hour at room temperature with phosphate-buffered saline (PBS; $1 \mathrm{~mol} \mathrm{l}^{-2}$ phosphate buffer, $2.7 \mathrm{~mol} \mathrm{l}^{-3}$ potassium chloride, and $1.37 \mathrm{~mol} \mathrm{l}^{-1}$ sodium chloride, $\mathrm{pH} 7.4$ ) containing $0.05 \%$ Tween 20 (v/v) (Sigma-Aldrich, Ireland) and 5\% low-fat milk powder (w/v) (Carnation Milk, Nestlé S.A., Vevey, Switzerland) to block non-specific binding.

Table 1 Patient Demographics of women with a BMI of $18.5-24.9 \mathrm{~kg} / \mathrm{m}^{2}(n=15)$

\begin{tabular}{lcccc}
\hline & $\begin{array}{c}\text { Age } \\
\text { (yrs) }\end{array}$ & $\begin{array}{c}\text { Gestation } \\
\text { (wks) }\end{array}$ & $\begin{array}{c}\text { Baby wt. } \\
(\mathbf{k g})\end{array}$ & BMI value \\
\hline Mean +/- SEM & $36.5+/-1.15$ & $38.5+/-0.2$ & $3.3+/-0.1$ & $24.0+/-0.3$ \\
Range & $29-45$ & $37-41$ & $2.6-4.2$ & $21.7-24.9$ \\
\hline
\end{tabular}


Table 2 Patient Demographics of women with a BMI of $\geq 30 \mathrm{~kg} / \mathrm{m}^{2}(n=22)$

\begin{tabular}{lcccc}
\hline & $\begin{array}{c}\text { Age } \\
\text { (yrs) }\end{array}$ & $\begin{array}{c}\text { Gestation } \\
\text { (wks) }\end{array}$ & $\begin{array}{c}\text { Baby } \\
\text { wt. }(\mathbf{k g})\end{array}$ & $\begin{array}{c}\text { BMI } \\
\text { value }\end{array}$ \\
\hline Mean $+/-$ SEM & $32.4+/-1.1^{*}$ & $39.0+/-0.1$ & $3.6+/-0.1^{*}$ & $33.8+/-0.9^{* * *}$ \\
Range & $19-39$ & $35-41$ & $2.6-4.7$ & $30.3-49.6$ \\
$\begin{array}{l}\text { *** indicates a significance value of } P<0.001,{ }^{*} \text { indicates a significance value } \\
\text { of } P<0.05 \text {, compared to the normal BMl group. }\end{array}$
\end{tabular}

\section{Western blot analysis}

Blots were incubated overnight in $1 \mathrm{X}$ PBS containing $0.05 \%$ Tween 20 and 5\% milk with the primary antibody at $4{ }^{\circ} \mathrm{C}$. The following primary antibodies $(1 / 50-1 / 500$ dilution) were utilised: anti-human ROCK-1 mouse polyclonal primary antibody (G-6 sc17794), ROCK-2 rabbit polyclonal G6 (sc5561), RhoA mouse monoclonal (26C4 sc418), caveolin-1 rabbit polyclonal (N-20 sc894), Rho8 (Rnd3) mouse monoclonal (clone 4 sc53874), moesin goat polyclonal (C-15 sc6410), pmoesin Thr558 goat polyclonal (sc12895), OTR rabbit polyclonal (H-60 sc33209), RhoGDI rabbit polyclonal (A20 sc360), MYPT 1 rabbit polyclonal (H-130 sc25718), MYL-9 (MLC) (D-15 sc-34487), ppMLC 18/19 goat polyclonal (sc12896 Santa Cruz Biotechnology Inc., Rockford, IL, USA), pMYPT 853 rabbit (Upstate, Millipore, Billerica, MA, USA), pMYPT Thr696 rabbit polyclonal (Upstate Millipore, USA ABS454), MLC mouse monoclonal (ab97981 Abcam plc, Milton Road, Cambridge, UK), RhoE (Rnd3) mouse monoclonal 3664 (Cell Signaling Technology, Danvers, MA, USA), caspase 3 monoclonal rabbit (Cell Signaling, USA 8G10 9665), cleaved caspase 3 rabbit monoclonal (Cell Signaling, USA Asp175 5A1E), calponin mouse monoclonal (DakoCytomation Ltd, UK M3556), pMAPK mouse monoclonal antibody to ERK1 and 2 pT185 and Y187 (Abcam, UK 50011) or 1/10,000 dilution of $\beta$-actin (ACTB) mouse monoclonal AC-15 (Sigma-Aldrich, Ireland) antibodies. Blots were washed and incubated in either $1 / 1,000$ dilution of donkey antigoat (Pierce Technology, Hallandale, FL., USA), 1/1000 goat anti-rabbit (Pierce Technology, USA), or 1/5000 dilution anti-mouse (Millipore, USA) horseradish peroxidaseconjugated secondary antibodies, the bound secondary antibody was detected as previously described. The membranes were then scanned with the fluorescence imager (FluorchemTM 8900, Alpha Innotech Corporation, San Leandro, California, USA) and AlphaEaseFC software was used to detect the signal, the image was processed and protein expression levels were determined by densitometric analysis compared to corresponding levels of the housekeeping protein, $\beta$-Actin [8].

\section{Statistical analysis}

Statistical 2-tailed unpaired student t-tests were performed on the means of each group in order to assess the differences between groups, and graphs were constructed using GraphPad Prism version 4 (GraphPad Software Inc., USA). The mean, significance $(P)$ values, standard error of the mean (SEM) and range values are presented in the text. $P$ values $<0.05$ were considered to be statistically significant.

\section{Results}

\section{Patient demographics}

The demographic details of all the patients in this study $(n=37)$ are contained in Tables 1 and 2 . We statistically analysed the p160 ROCK-1 expression results in relation to maternal age alone; the mean \pm SEM for women of less than 35 years $(n=14)$ was $0.71 \pm 0.05$, the mean for women aged 35 years and over $(n=23)$ was $0.89 \pm 0.07$ $(P=0.08)$. Parity for those in the normal BMI group was 0 : 6 women, 1: 8 women and $\geq 2: 1$ woman and for those in obese group, 0: 13 women, 1: 8 women and $\geq 2: 1$ woman.

\section{Western blots}

The expression of p160 ROCK-1 protein was significantly reduced in the myometrium from women in the obese category $(n=22)$ compared to women from the normal BMI group $(n=15)$ (Figure 1). The densitometric mean \pm SEM of the normal BMI group was $1.003 \pm 0.0075$ (range 0.72 - 1.66) compared to $0.4912 \pm 0.033$ for the obese group (range $0.19-0.73$ ), $P<0.001$.

In a representative Western blot, the expression of p160 ROCK-1 was demonstrated to be significantly decreased

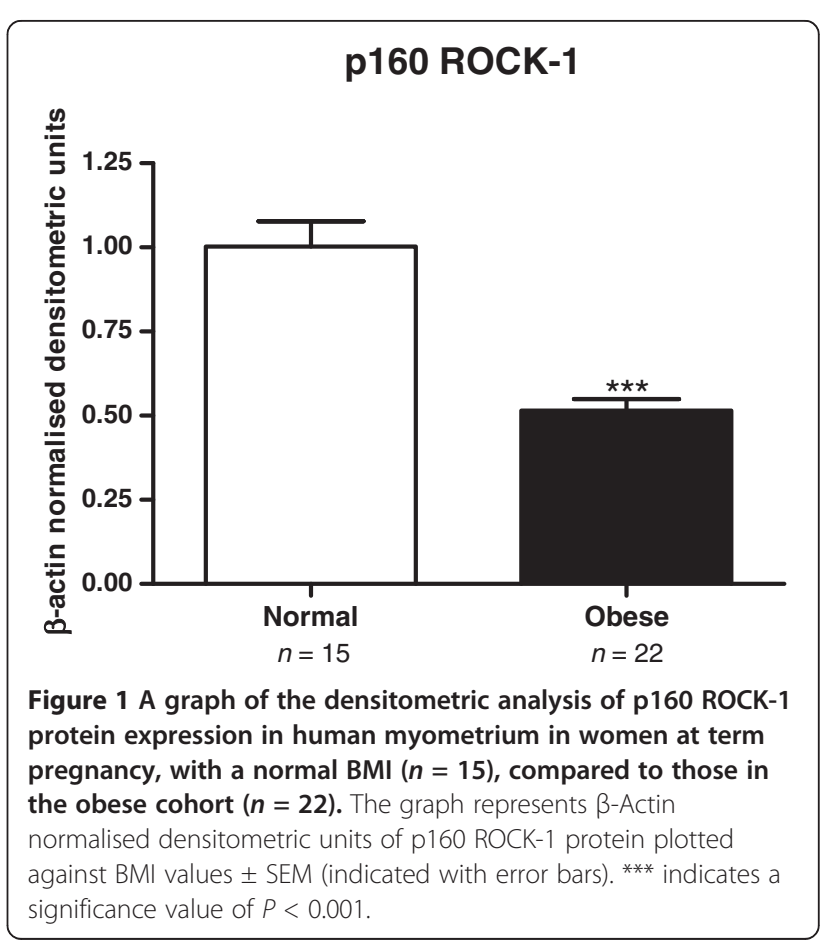


in the myometrium from women in the obese category $(n=7)$, compared to women from the normal BMI cohort $(n=7)(P=0.0007)$ (Figure 2). The expression of a lower band in the ROCK-1 western blots was also observed to be increased in the samples that demonstrated a significant reduction in p160 ROCK-1 protein expression. In this experiment the expression of the lower band was observed to significantly increase in the same obese samples as those above $(P=0.0064)$ (Figure 2).

The mean densitometric units for the expression of p160 ROCK- 1 in the normal BMI group was 0.584 \pm 0.044 , the range was 0.44 to 0.76 . The mean densitometric value for the p160 ROCK-1 protein in the high BMI group was $0.34 \pm 0.032$ (range $0.22-0.49$ ).

The mean value for the lower band in the p160 ROCK-1 blot for the normal BMI group was $0.151 \pm 0.012$ (range 0.11 to 0.185 ). The mean expression value of the lower band in the high BMI group was $0.269 \pm 0.034$ (range $0.16-0.39$ ).

There were a series of proteins for which expression was detected in samples but there was no alteration thereof noted between the myometrium from the women of normal BMI, and that obtained from women in the obese category BMI. A list of these proteins is as follows: RhoA, Rho kinase 2 (ROCK-2), Rho guanine nucleotide dissociation inhibitor (RhoGDI), both phosphorylated and unphosphorylated myosin light chain (MLC and ppMLC 18/19), phosphorylated and unphosphorylated myosin phosphatase (MYPT and pMYPT 696 and pMYPT 853), Rho family protein Rnd3, oxytocin receptor (OTR), phosphorylated mitogen-activated protein kinase (pMAPK), caspase 3, phosphorylated moesin

(a)
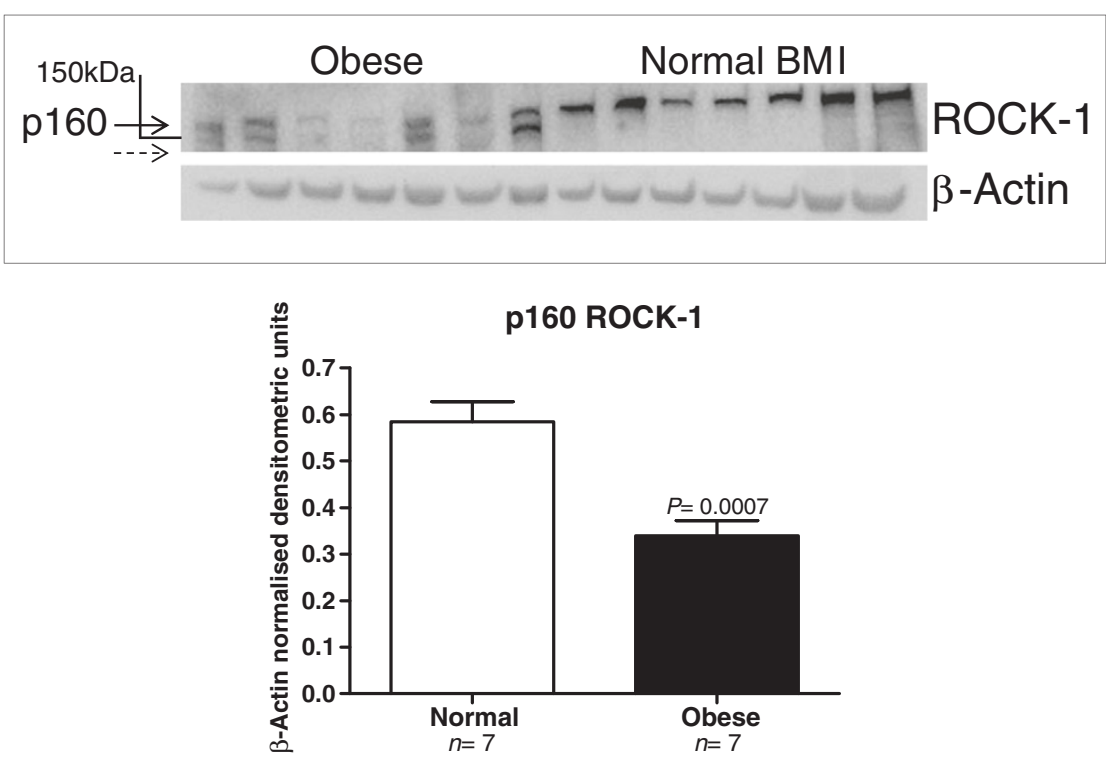

(b)

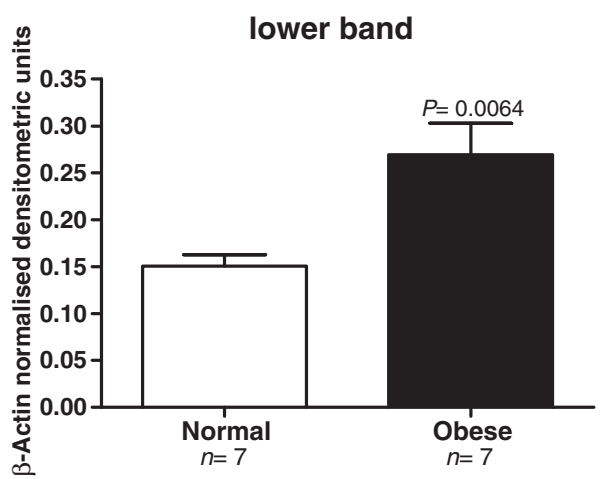

Figure 2 A representative western blot of p160 ROCK-1 protein expression in myometrium from women with normal BMI $(n=7)$ compared to those in the obese category $(\boldsymbol{n}=\mathbf{7})$. The top band in the first blot indicated with the arrow is p160 ROCK-1 while the lower unidentified band, indicated with the broken arrow, was also quantified. The corresponding $\beta$-Actin western blot is also presented. The molecular weights $(\mathrm{kDa})$ are represented by a line (a). Quantitative densitometric analyses of the expression of the p160 ROCK-1 and the lower band are presented below the western blots, with $\beta$-Actin-normalised densitometric units plotted against BMI values, at term pregnancy \pm SEM (indicated with error bars). The significance values $(P)$ are indicated $(\mathbf{b})$. 
(pMoesin), caveolin-1 and calponin. This is demonstrated in Figures 3 and 4.

\section{Discussion}

The findings from this study demonstrate a decrease in p160 ROCK-1 protein expression in the myometrium of obese pregnant women at term. This is an interesting finding considering the putative dysfunctional uterine activity that is believed to occur in obese pregnant women undergoing labour. The reasons for, or significance of, this finding are unclear but it is tempting to speculate that such reduced expression might exert a negative effect on
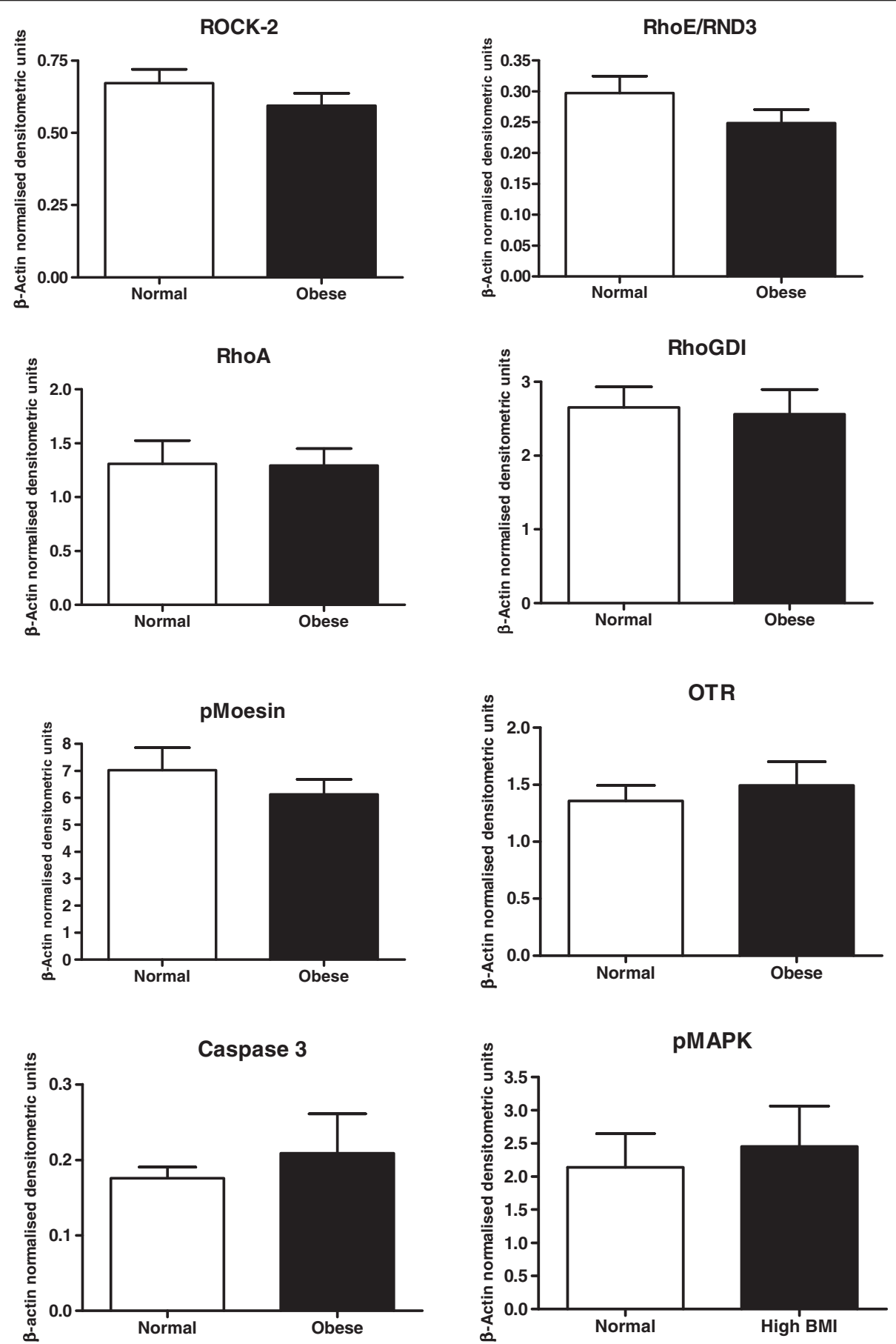

Figure 3 Graphs of the densitometric analyses of the expression of RhoA/ROCK associated proteins, ROCK-2, RhoE, RhoA, RhoGDI, OTR in human myometrium from women with normal BMI $(n=15)$, compared to those in the obese category $(n=22)$, and caspase 3, pmoesin and pMAPK ( $n=7$ for both groups). 

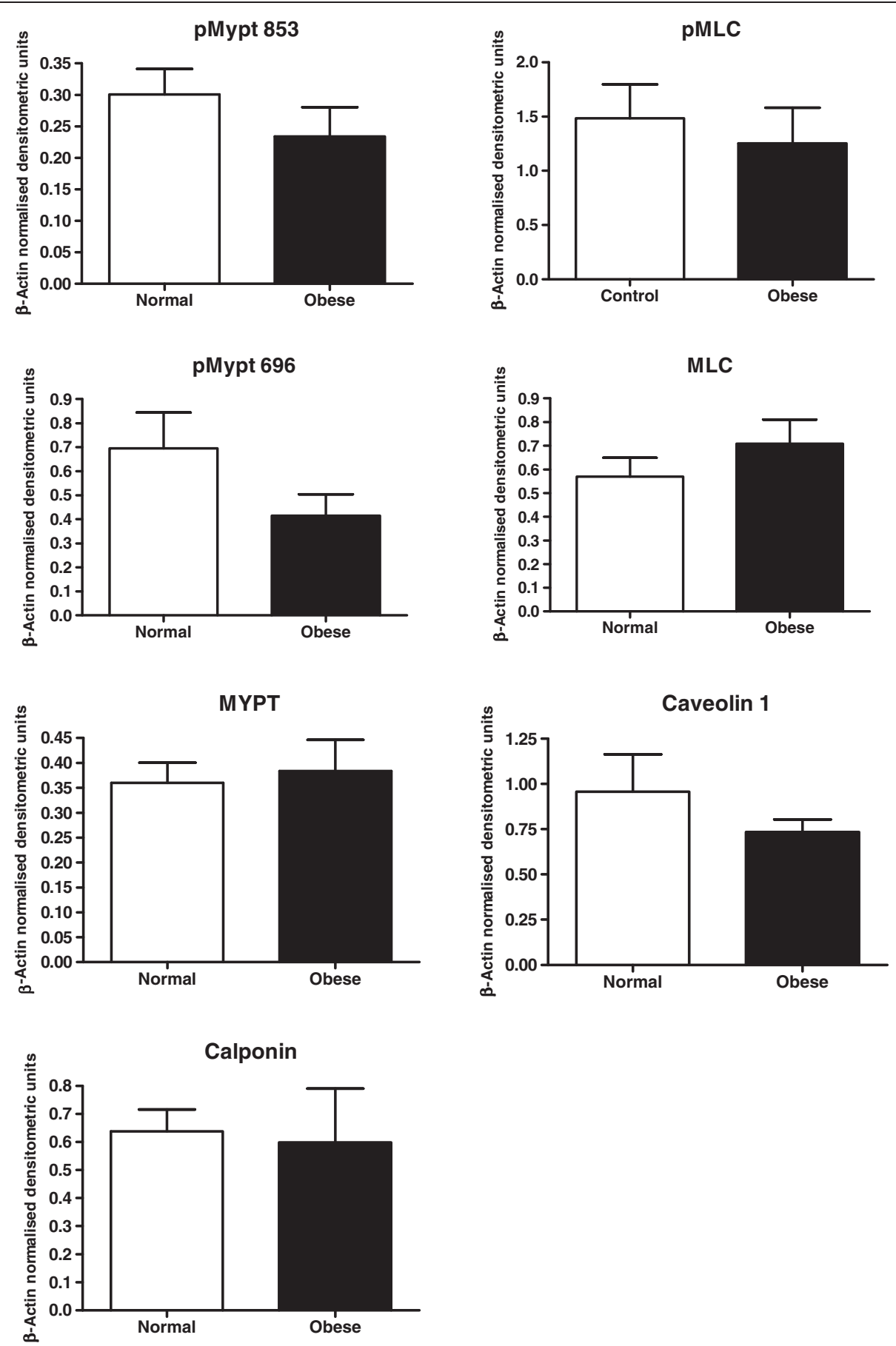

Figure 4 Graphs of the densitometric analyses of the expression of RhoA/ROCK associated proteins, (p)(p)MYPT and (pp)MLC in human myometrium from women with normal BMI $(n=15)$, compared to those in the obese category $(n=22)$, and calponin and caveolin-1 ( $n=7$ for both groups).

uterine contractility in obese women, given the role of p160 ROCK-1 in calcium sensitisation, and also the roles it plays in other signalling pathways linked to contractility $[10,12]$. The strengths of this study are that the experiments were carried out in a relatively large number of samples, the clinical and BMI data are all reliable, the samples were collected and frozen freshly, there was no apparent difference in relation to maternal age, and there was a large difference in the expression levels observed. The limitations of this study include the fact that protein expression was investigated, but not protein activity, and that all samples were obtained prior to the onset of labour. 
In addition we have not related the findings observed in a functional model. The potential signalling pathways that may mediate the effects of such reduced expression are many, and this would require an extensive series of pharmacological experiments, which is a topic for further study.

As a consequence of the finding of reduced expression of p160 ROCK-1 in myometrium from pregnant women at term, and the suggestion that this may compromise the capacity of the myometrium to contract adequately, we subsequently examined the expression of other members of the RhoA/ROCK pathway. There was no change in RhoA, ROCK-2, Rnd3, calponin, OTR or caveolin-1 protein expression in association with increased maternal BMI. Similarly no change was observed in myometrial MYPT and MLC protein expression and phosphorylation, or the phosphorylation of the ROCK effector proteins moesin and MAPK. It is difficult to propose an overall mechanism of effect linked to the reduced p160 ROCK-1 expression observed, but the concept remains that it may be clearly linked to reduced myometrial contractility.

What could be responsible for the decrease in ROCK-1 expression? One possibility is that secretory factors produced by adipose tissue of overweight and obese women may alter the myometrial physiology. More than 100 substances including adipocytokines are secreted from the adipose tissue [21]. Interestingly, there is an altered contribution of RhoA/Rho kinase signalling in contractile activity of myometrium in leptin receptor-deficient mice. The authors of this latter study demonstrated that leptin suppressed myometrial ROCK-1 and 2 expression and function, resulting in an inability to generate tonic contractions needed for delivery [18]. Thus, it is possible that increased leptin levels in obese pregnant women might be in part responsible for the reduction in ROCK-1 protein expression, and may result in reduced myometrial contractility.

Another possibility in consideration of the results of this study is that p160 ROCK-1 protein reduction occurs, secondary to protein cleavage. The appearance of the lower band in the ROCK-1 western blots prompted us to investigate protease involvement in the decline of the p160 ROCK-1 protein. Elevated caspase 3 levels have been noted in pregnant mouse, rat and human uterus where it is thought to be involved in the regulation of uterine quiescence [22-24]. We did detect Caspase 3 protein in the myometrial biopsies however there was no significant change in expression and no observable cleaved caspase-3 protein. Indeed, phosphorylation of p160 ROCK-1 or other biochemical mechanisms may be responsible for the additional band. However, further investigation is necessary on this matter.

\section{Conclusions}

ROCK-1 plays a central role in myometrial contractility and is closely linked to other signalling molecules in the cell. The reduction in its expression demonstrated in this study in the myometrium of obese pregnant women at term may play a role in inhibiting contractility in these women.

\section{Competing interests \\ The authors' declare that they have no competing interests.}

\section{Authors' contributions}

$\mathrm{MOB}$ conceived the idea and design of the project, collected myometrial biopsies, isolated protein, performed the western blots, did the statistical analysis and drafted the manuscript. SC collected myometrial biopsies and prepared tissue protein. JJM provided access to the myometrial tissue samples and patient data, and edited the final document. TJS acquired funding. All authors read and approved the final manuscript.

\section{Acknowledgements}

The authors are grateful to the medical and midwifery staff at University College Hospital Galway for their assistance with patient recruitment and tissue collection. This study was funded by the Health Research Board of Ireland and the Higher Education Authority of Ireland's Programme for Research in Third Level Institutions and the National University of Ireland, Galway.

\section{Author details}

${ }^{1}$ Department of Obstetrics and Gynaecology, Clinical Sciences Institute, University College Hospital Galway, Galway, Ireland. ${ }^{2}$ National Centre for Biomedical and Engineering Science, Orbsen Building, National University of Ireland, Galway University Road, Galway, Ireland.

Received: 5 March 2013 Accepted: 7 August 2013

Published: 15 August 2013

\section{References}

1. Hehir MP, Morrison JJ: The adipokine apelin and human uterine contractility. Am J Obstet Gynecol 2012, 206(359):e351-355.

2. Cedergren Ml: Maternal morbid obesity and the risk of adverse pregnancy outcome. Obstet Gynecol 2004, 103:219-224.

3. Zhang J, Bricker L, Wray S, Quenby S: Poor uterine contractility in obese women. BJOG 2007, 114:343-348.

4. Cedergren MI: Non-elective caesarean delivery due to ineffective uterine contractility or due to obstructed labour in relation to maternal body mass index. Eur J Obstet Gynecol Reprod Biol 2009, 145:163-166.

5. Jie Z, Kendrick A, Quenby S, Wray S: Contractility and calcium signaling of human myometrium are profoundly affected by cholesterol manipulation: implications for labor? Reprod Sci 2007, 14:456-466.

6. Moynihan AT, Hehir MP, Glavey SV, Smith TJ, Morrison JJ: Inhibitory effect of leptin on human uterine contractility in vitro. Am J Obstet Gynecol 2006, 195:504-509.

7. Hehir MP, Glavey SV, Morrison JJ: Uterorelaxant effect of ghrelin on human myometrial contractility. Am J Obstet Gynecol 2008, 198(323):e321-325.

8. O'Brien M, Earley P, Morrison JJ, Smith TJ: Ghrelin in the human myometrium. Reprod Biol Endocrinol 2010, 8:55.

9. Kamm KE, Stull JT: The function of myosin and myosin light chain kinase phosphorylation in smooth muscle. Annu Rev Pharmacol Toxicol 1985, 25:593-620.

10. Somlyo AP, Somlyo AV: Ca2+ sensitivity of smooth muscle and nonmuscle myosin II: modulated by G proteins, kinases, and myosin phosphatase. Physiol Rev 2003, 83:1325-1358.

11. Khromov A, Choudhury N, Stevenson AS, Somlyo AV, Eto M: Phosphorylation-dependent autoinhibition of myosin light chain phosphatase accounts for $\mathrm{Ca} 2+$ sensitization force of smooth muscle contraction. J Biol Chem 2009, 284:21569-21579.

12. Hudson CA, Heesom KJ, Lopez Bernal A: Phasic contractions of isolated human myometrium are associated with Rho-kinase (ROCK)-dependent phosphorylation of myosin phosphatase-targeting subunit (MYPT1). Mol Hum Reprod 2012, 18:265-279. 
13. Somlyo AP, Somlyo AV: Signal transduction by G-proteins, rho-kinase and protein phosphatase to smooth muscle and non-muscle myosin II. J Physiol 2000, 522(Pt 2):177-185.

14. O'Brien M, Flynn D, Mullins B, Morrison JJ, Smith TJ: Expression of RHOGTPase regulators in human myometrium. Reprod Biol Endocrinol 2008, 6:1.

15. Friel AM, Curley M, Ravikumar N, Smith TJ, Morrison JJ: Rho A/Rho kinase mRNA and protein levels in human myometrium during pregnancy and labor. J Soc Gynecol Investig 2005, 12:20-27.

16. Riley M, Baker PN, Tribe RM, Taggart MJ: Expression of scaffolding, signalling and contractile-filament proteins in human myometria: effects of pregnancy and labour. J Cell Mol Med 2005, 9:122-134.

17. Lartey J, Smith M, Pawade J, Strachan B, Mellor H: Lopez Bernal A: Upregulation of myometrial RHO effector proteins (PKN1 and DIAPH1) and CPI-17 (PPP1R14A) phosphorylation in human pregnancy is associated with increased GTP-RHOA in spontaneous preterm labor. Biol Reprod 2007, 76:971-982.

18. Harrod JS, Rada CC, Pierce SL, England SK, Lamping KG: Altered contribution of RhoA/Rho kinase signaling in contractile activity of myometrium in leptin receptor-deficient mice. Am J Physiol Endocrinol Metab 2011, 301:E362-369.

19. O'Brien M, Morrison JJ, Smith TJ: Expression of prothrombin and protease activated receptors in human myometrium during pregnancy and labor. Biol Reprod 2008, 78:20-26.

20. Condon JC, Hardy DB, Kovaric K, Mendelson CR: Up-regulation of the progesterone receptor (PR)-C isoform in laboring myometrium by activation of nuclear factor-kappaB may contribute to the onset of labor through inhibition of PR function. Mol Endocrinol 2006, 20:764-775.

21. Hauner $\mathrm{H}$ : Secretory factors from human adipose tissue and their functional role. Proc Nutr Soc 2005, 64:163-169.

22. Jeyasuria P, Wetzel J, Bradley M, Subedi K, Condon JC: Progesteroneregulated caspase 3 action in the mouse may play a role in uterine quiescence during pregnancy through fragmentation of uterine myocyte contractile proteins. Biol Reprod 2009, 80:928-934.

23. Joswig A, Gabriel HD, Kibschull M, Winterhager E: Apoptosis in uterine epithelium and decidua in response to implantation: evidence for two different pathways. Reprod Biol Endocrinol 2003, 1:44

24. Shynlova O, Oldenhof A, Dorogin A, Xu Q, Mu J, Nashman N, Lye SJ: Myometrial apoptosis: activation of the caspase cascade in the pregnant rat myometrium at midgestation. Biol Reprod 2006, 74:839-849.

doi:10.1186/1477-7827-11-79

Cite this article as: O'Brien et al:: Decreased myometrial p160 ROCKexpression in obese women at term pregnancy . Reproductive Biology and Endocrinology 2013 11:79.

\section{Submit your next manuscript to BioMed Central and take full advantage of:}

- Convenient online submission

- Thorough peer review

- No space constraints or color figure charges

- Immediate publication on acceptance

- Inclusion in PubMed, CAS, Scopus and Google Scholar

- Research which is freely available for redistribution 